\title{
MicroRNA-218 inhibits the malignant phenotypes of glioma by modulating the TNC/AKT/AP-1/TGFß1 feedback signaling loop
}

\author{
SIWEN DANG $^{1 *}$, RUI ZHANG ${ }^{1 *}$, SIJIA TIAN ${ }^{1}$, PENG HOU $^{1}$, GANG LI $^{2}$ and MEIJU JI ${ }^{3}$ \\ ${ }^{1}$ Key Laboratory for Tumor Precision Medicine of Shaanxi Province and Department of Endocrinology, \\ The First Affiliated Hospital of Xi'an Jiaotong University, Xi'an, Shaanxi 710061; ${ }^{2}$ Department of Neurosurgery, \\ Tangdu Hospital, Air Force Medical University, Xi'an, Shaanxi 710038; ${ }^{3}$ Center for Translational Medicine, \\ The First Affiliated Hospital of Xi'an Jiaotong University, Xi'an, Shaanxi 710061, P.R. China
}

Received March 10, 2021; Accepted July 30, 2021

DOI: $10.3892 / \mathrm{ijmm} .2021 .5038$

\begin{abstract}
Gliomas are the most malignant and common tumors of the human brain, and the prognosis of glioma patients is extremely poor. MicroRNAs (miRNAs or miRs) play critical roles in different types of cancer by performing post-transcriptional regulation of gene expression. Although miR-218 has been demonstrated to be decreased in gliomas, its role in gliomas remains largely unknown. miR-218 expression was analyzed in gliomas and normal brain tissues (control subjects) using a dataset from The Cancer Genome Atlas. A series of in vitro and in vivo studies were performed to determine the biological roles of miR-218 in glioma cells. Potential targets of miR-218 were identified using a dual-luciferase reporter system. Western blot and dual-luciferase reporter system experiments were performed to evaluate the regulatory effect of miR-218 on the tenascin C (TNC)/AKT/activator protein 1 (AP-1)/transforming growth factor $\beta 1$ (TGF $\beta 1$ ) pathway. It was demonstrated that miR-218 was significantly downregulated in gliomas compared with control subjects, and played potent tumor suppressor roles in glioma cells by inhibiting cell proliferation, colony formation, migration, invasion and tumorigenic potential in nude mice, as well as inducing cell cycle arrest and apoptosis. Mechanistically, miR-218 inhibited malignant phenotypes of glioma cells by binding to the 3'-untranslated region of its target TNC and subsequently suppressing its expression. As a result, miR-218 could reduce
\end{abstract}

Correspondence to: Dr Meiju Ji, Center for Translational Medicine, The First Affiliated Hospital of Xi'an Jiaotong University, 277 Yanta West Road, Xi'an, Shaanxi 710061, P.R. China

E-mail: mjji0409@xjtu.edu.cn

Dr Gang Li, Department of Neurosurgery, Tangdu Hospital, Air Force Medical University, 569 Xinsi Road, Xi'an, Shaanxi 710038, P.R. China

E-mail: liliangxbyt@aliyun.com

*Contributed equally

Key words: glioma, microRNA-218, tenascin C, AKT/activator protein $1 /$ transforming growth factor $\beta 1$ signaling axis, tumorigenesis
AKT phosphorylation and subsequently inhibit transcriptional activity of AP-1 by reducing JNK phosphorylation, downregulating the expression of TGF $\beta 1$, while TGF $\beta 1$ was able to, in turn, activate the TNC/AKT/AP-1 signaling axis. Our data revealed a previously unknown tumor suppressor role of miR-218 by blocking the TNC/AKT/AP-1/TGF $\beta 1$-positive feedback loop in glioma.

\section{Introduction}

Gliomas, which represent $\sim 70 \%$ of all brain tumors, are the most malignant and common tumors in the human brain (1). Currently, a combination of chemotherapy and radiation following maximal safe surgical resection is the standard treatment for newly diagnosed patients with glioma $(2,3)$. However, despite these treatments, the overall survival rate of patients with glioma continues to be among the lowest of all the main types of cancer (4). Thus, it is important to understand the molecular mechanism of its pathogenesis to develop effective therapeutic strategies for glioma.

MicroRNAs (miRNAs/miRs) can bind to the 3'-untranslated region (UTR) of target mRNAs and induce translational suppression, mRNA destabilization or cleavage to perform post-transcriptional regulation of gene expression (5-9). Increasing evidence has indicated that miRNAs, as small non-coding single-stranded RNA molecules, are critical in the tumorigenesis and development of different types of cancer, including gliomas (10-13). Among them, downregulated miR-218 expression has been reported in gliomas, but not in normal brain tissues (14-16), which is closely associated with poor overall survival and disease-free survival in patients with glioma $(17,18)$. Notably, miR-218 contains miR-218-1 and miR-218-2, located on chromosome 4p15.31 and 5q35.1, respectively, which have different $3 p$ sequences, but the same $5 p$ sequences as miR-218-5p (19). However, the role of miR-218 in glioma remains unclear.

The present study identified tenascin C (TNC) as a novel target of miR-218, which is a major constituent of the extracellular matrix in the developing brain, and can be re-expressed in wound healing, inflammation and tumors (20-23). TNC expression is upregulated in gliomas, and is significantly associated with poor patient survival and malignant 
progression (24). It has been reported that TNC may be a promising therapeutic target for glioma (25). miR-218 was confirmed as a potential tumor suppressor in glioma by blocking the TNC/AKT/activator protein-1 (AP-1)/transforming growth factor $\beta 1$ (TGF $\beta 1$ )-positive feedback loop via a series of in vitro and in vivo experiments.

\section{Materials and methods}

The Cancer Genome Atlas (TCGA) analysis. The miRNAs and TNC expression profiles of TGCA-low-grade glioma (LGG) dataset and the clinical information were obtained from TCGA database (https://portal. gdc.cancer.gov/) (26). A total of 5 normal brain tissues and 526 LGG tissues from the TCGA database were obtained. Patients without clinical information, including age, sex, TNM stage, histological grades, survival, and without miR-218-1, miR-218-2 and TNC expression data were excluded. An unpaired Student's t-test was used to compare gene expression in two groups of tissues. Survival analysis was performed using the Kaplan-Meier method and log-rank test. The association between TNC expression and miR-218s expression was analyzed via linear regression.

Reverse transcription-quantitative $(R T-q) P C R$. TRIzol reagent (Takara Biotechnology Co., Ltd.) was used to extract total RNA from cell lines and tissues following the manufacturer's protocol. The cDNA was synthesized with $500 \mathrm{ng}$ total RNA using PrimeScript RT reagent kit (Takara Biotechnology Co., Ltd.) according to the manufacturer's instructions. qPCR was carried out on a CFX96 Thermal Cycler Dice ${ }^{\mathrm{TM}}$ real-time PCR system (Bio-Rad Laboratories, Inc.) using SYBR Premix Ex Taq ${ }^{\mathrm{TM}}$ (Takara Biotechnology Co., Ltd.), as previously described (27). The amplification conditions were as follows: Stage 1 (holding $95^{\circ} \mathrm{C}$ for $10 \mathrm{~min}$ ); stage 2 (40 cycles of denaturing at $95^{\circ} \mathrm{C}$ for $15 \mathrm{sec}$, annealing at $60^{\circ} \mathrm{C}$ for $45 \mathrm{sec}$ and extending at $72^{\circ} \mathrm{C}$ for $30 \mathrm{sec}$ ); stage 3 (extension at $72^{\circ} \mathrm{C}$ for $7 \mathrm{~min}$ ). The relative expression levels were calculated using the $2^{-\Delta \Delta C q}$ method (28). RT-qPCR analysis was performed using the primer sequences listed in Table SI. Relative expression levels were normalized to $18 S$ rRNA cDNA. The gene-specific RT primer sequences listed in Table SII were synthesized to reverse transcribe the indicated miRNAs into cDNA. The primer sequences for miRNAs are listed in Table SIII, and expression levels were normalized to the internal reference gene U6. All experiments were performed in triplicate.

Cell culture. The human glioma cell lines, U251 and SHG44, were purchased from the Laboratory Animal Center of Sun Yat-sen University (Guangzhou, China). Cells were maintained in DMEM (Invitrogen; Thermo Fisher Scientific, Inc.) supplemented with 10\% FBS (Biological Industries), $100 \mathrm{IU} / \mathrm{ml}$ penicillin and $100 \mu \mathrm{g} / \mathrm{ml}$ streptomycin, at $37^{\circ} \mathrm{C}$ in a humidified atmosphere with $5 \% \mathrm{CO}_{2}$. All cell lines used in this study were authenticated by short tandem repeat (STR) analysis using the Cell ID System (Promega Corporation) in March 2019 with maximum 20 passages before the cells were analyzed. Meanwhile, the one-step Quickcolor Mycoplasma Detection kit (Shanghai Yise Medical Technology Co., Ltd.; http://www.yisemed.com) was used according to the manufacturer's instructions, to demonstrate that these cell lines were not contaminated by mycoplasma. In some experiments, cells were treated with recombinant human TGF $\beta 1$ proteins (10 ng/ml; Sino Biological, Inc.) for $24 \mathrm{~h}$. The control group had the same volume of a vehicle.

Mimics and lentivirus transfection. miR-218 mimics (sense: 5'-UUGUGCUUGAUCUAACCAUGU-3') and negative control (NC) mimics (sense: 5'-UUUGUACUACACAAA AGUACUG-3') (Guangzhou RiboBio, Co., Ltd.) (25 nM) were transfected into a total of $1 \times 10^{5}$ cells using Lipofectamine ${ }^{\circledR}$ 3000 (Invitrogen; Thermo Fisher Scientific, Inc.) (at $37^{\circ} \mathrm{C}$ for $24 \mathrm{~h}$ ), according to the manufacturer's protocols, in three replicates. Subsequent experimentation were performed following $48 \mathrm{~h}$ of transfection.

A lentivirus encoding miR-218 (Ubi-MVC-SV40EGFP-IRES-Puro-miR-218) and control lentivirus (Ubi-MVC-SV40-EGFP-IRES-Puro) were purchased from Shanghai GeneChem Co., Ltd. [obtained from 293T cells (purchased from Cell Bank of Chinese Academy of Sciences; cat. no. GNHu17) by transient transfection of lentivirus construct $(20 \mu \mathrm{g})$ as well as helper plasmids pHelper 1.0 $(15 \mu \mathrm{g})$ and pHelper $2.0(10 \mu \mathrm{g})]$. The lentiviruses were transfected into a total of $1 \times 10^{5} \mathrm{U} 251$ cells, with 20-100 final lentivirus multiplicity of infection at $50 \%$ confluence, in the presence of $8 \mu \mathrm{g} / \mathrm{ml}$ polybrene (at $37^{\circ} \mathrm{C}$ for $24 \mathrm{~h}$ ), and replaced with fresh medium after $24 \mathrm{~h}$. Following $72 \mathrm{~h}$ of infection, the fluorescence expression was observed by fluorescence microscope at a magnification of $x 100$. Then the cells were selected using puromycin $(2 \mu \mathrm{g} / \mathrm{ml})$ to establish stable cell lines. These lentiviruses were only used in the nude mice tumorigenesis experiment.

MTT assay. After $48 \mathrm{~h}$ of transfection, cell numbers were counted with a hemocytometer. A total of 5,000 cells/well were then seeded into per 96-well plates. Following incubation for $0,1,3,5$ and 7 days, cells were incubated with 3-(4,5-dimethylthiazol-2-yl)-2, 5-diphenylte tetrazolium bromide (MTT; $200 \mu \mathrm{l} /$ well Sigma Aldrich; Merck $\mathrm{KGaA}$ ) for $4 \mathrm{~h}$ at $37^{\circ} \mathrm{C}$. Subsequently, $150 \mu \mathrm{l}$ of dimethyl sulfoxide was supplemented to each well and mixed for $15 \mathrm{~min}$. The absorbance of each well was determined with an ultraviolet spectrophotometer at $490 \mathrm{~nm}$.

Soft agar colony formation assay. A bottom layer of $2 \mathrm{ml}$ DMEM supplemented with $0.7 \%$ agar and $10 \%$ FBS and a top layer of $1 \mathrm{ml}$ DMEM supplemented with $0.35 \%$ agar and $10 \%$ FBS were added in 6-well plates, which contained 3,000 cells/well and were then incubated for 2-3 weeks at $37^{\circ} \mathrm{C}$. Subsequently, with a diameter $\geq 200 \mu \mathrm{m}$, the total number and sizes of colonies were calculated using a light microscope (Olympus Corporation) in $>5$ fields per well for a total of 15 fields in triplicate experiments.

Cell cycle assay. After $48 \mathrm{~h}$ of transfection, a total of $1 \times 10^{5}$ cells/well were then seeded into 6-well plates. Cells, which were maintained in DMEM without FBS for $24 \mathrm{~h}$ to induce cell cycle synchronization, and then maintained in DMEM supplemented with 10\% FBS for another $24 \mathrm{~h}$, were digested. After centrifugation at $500 \mathrm{x}$ g for $3 \mathrm{~min}$ at $4^{\circ} \mathrm{C}$, the cells was washed once with PBS, and stored in 
cold $70 \%$ ethanol at $-20^{\circ} \mathrm{C}$ overnight after washed with $4{ }^{\circ} \mathrm{C}$ PBS. Subsequently, the cells were stained with $500 \mu \mathrm{l}$ PBS supplemented propidium iodide (PI) $(50 \mu \mathrm{g} / \mathrm{ml})$ and RNase A (100 U/ml) (at $4^{\circ} \mathrm{C}$ for $30 \mathrm{~min}$ ) and detected by flow cytometry (FACScan; BD Biosciences) for cell cycle analysis using the FlowJo software (v10.5; Tree Star, Inc.).

Apoptotic cell assay. After $48 \mathrm{~h}$ of transfection, a total of $5 \times 10^{6}$ cells/well were digested, incubated with $5 \mu \mathrm{l}$ FITC-Annexin buffer and stained with $5 \mu \mathrm{l}$ PI at room temperature for $10 \mathrm{~min}$, using an Annexin V-Fluorescein isothiocyanate (FITC) Apoptosis Detection kit I (BD Biosciences), according to the manufacturer's instructions, and detected by flow cytometry (FACScan; BD Biosciences) for apoptotic cell assays using the FlowJo software (v10.5; Tree Star, Inc.).

Transwell assays. Transwell chambers $(8.0-\mu \mathrm{m}$ pore size; Corning Life Sciences) coated with Matrigel (incubated at $37^{\circ} \mathrm{C}$ for 4-5 h to make it dry and gelatinous) (BD Biosciences) or not coated by Matrigel, on the upper chamber were used to assess cell invasion and migration abilities, respectively. After $48 \mathrm{~h}$ of transfection, $5 \times 10^{4}$ cells were seeded to the upper chamber, which contained $200 \mu \mathrm{l}$ serum-free medium (DMEM). The bottom chamber was filled with $1 \mathrm{ml}$ of medium containing $10 \% \mathrm{FBS}$. After incubation for $48 \mathrm{~h}$ at $37^{\circ} \mathrm{C}$, the number of cells in the bottom chamber were determined by $1 \%$ crystal violet staining (at room temperature for $30 \mathrm{~min}$ ) and quantified using an inverted light microscope (Olympus Corporation) in 10 random fields. All assays were performed as previously described (27). All experiments were performed in triplicate.

Western blot analysis. Cells were lysed in prechilled RIPA buffer (Cell Signaling Technology, Inc.) containing protease inhibitors. The protein concentration was determined using A280 absorbance measurements by NanoDrop2000 Ultra Micro Spectrophotometer (Thermo Fisher Scientific, Inc.). Equal amounts (100 $\mu \mathrm{g}$ per lane) of protein lysates were separated by $10 \%$ SDS-PAGE and transferred to PVDF membranes (Roche Diagnostics $\mathrm{GmbH}$ ), and then blocked with $10 \%$ skimmed milk at $37^{\circ} \mathrm{C}$ for $2 \mathrm{~h}$. Next, the membranes were incubated with the indicated primary antibodies (Table SIV) (TNC, 1:500; phospho-Akt Ser473, 1:1,000; phospho-Akt Thr308, 1:1,000; total AKT, 1:1,000; phospho-JNK, 1:500; total JNK, 1:1,000; JUN 1:1,000; FOS, 1:1,000; TGF $\beta 1,1: 1,000 ; \beta$-actin, $1: 2,000)$ at $4^{\circ} \mathrm{C}$ overnight. After incubation of the membranes with species-specific HRP-conjugated secondary antibodies, goat anti-rabbit antibody (1:3,000; cat. no. TA130023; OriGene Technologies, Inc.) or goat anti-mouse antibody (1:3,000; TA130004; OriGene Technologies, Inc.), for $2 \mathrm{~h}$ at $37^{\circ} \mathrm{C}$, the Western Bright ECL detection system (Advansta, Inc.) was used to visualize the immunoblotting signals.

Prediction of miRNA target genes. miR-218-5p-targeted genes were predicted with different bioinformatic algorithms from various databases, including miRanda (http://www. microrna.org/microrna/home.do), TargetScan 3.0 (http://www. targetscan.org/) and miRDB (http://mirdb.org/). The overlapping genes were analyzed.
Dual-luciferase reporter assay. The wild-type (WT) TNC 3'-UTR was amplified from cDNA of U251 cells to construct the luciferase reporter plasmids. The TNC 3'-UTR with mutant (MUT) binding site of miR-218 was synthesized by Sangon Biotech Co., Ltd. These two fragments were inserted into pre-digested pmirGLO luciferase vector (gifted by Dr Yanke Chen at Xi'an Jiaotong University Health Science Center) to produce the luciferase reporter plasmids, pmirGLO-TNC 3'-UTR-WT and pmirGLO-TNC 3'-UTR-MUT. The primer sequences for plasmid constructs are listed in Table SV. The 3xAP in $\mathrm{pGL} 3$-Basic luciferase reporter plasmid was purchased from Addgene, Inc. (plasmid no. 40342), which contains three canonical AP-1 binding sites (TGACTCA) upstream of the luciferase reporter plasmid pGL3-Basic promoter fragment.

To assess the 3'-UTR activity of TNC mRNA modulated by miR-218, U251 and SHG44 cells were transfected with NC or miR-218-mimics in 6-well plates and subsequently co-transfected with pmirGLO-TNC 3'-UTR-WT or pmirGLO-TNC 3'-UTR-MUT, using Lipofectamine ${ }^{\circledR} 3000$ (Invitrogen; Thermo Fisher Scientific, Inc.). To determine transcriptional activity of AP-1 regulated by miR-218 or TGF $\beta 1$, U251 and SHG44 cells were treated with TGF $\beta 1\left(10 \mathrm{ng} / \mathrm{ml}\right.$; at $37^{\circ} \mathrm{C}$ for $24 \mathrm{~h}$ ) or transfected with $\mathrm{NC} / \mathrm{miR}-218$-mimics, and were subsequently co-transfected with pRL-TK plasmids and the 3xAP in pGL3-Basic luciferase reporter plasmid. Following incubation for $36 \mathrm{~h}$, luciferase activities were detected using a dual-luciferase reporter assay system (Promega Corporation) on an EnSpire Multimode Plate Reader (PerkinElmer, Inc.). Firefly luciferase activity was normalized to Renilla luciferase activity. All experiments were performed in triplicate.

Animal studies. A total of 10 male athymic mice (3-4 weeks-old; weight $17.82 \pm 3.09 \mathrm{~g}$ ) were obtained from Shanghai SLAC Laboratory Animal Co., Ltd. A total of 5 mice were housed in a cage with a controlled temperature $\left(22 \pm 2^{\circ} \mathrm{C}\right)$ and humidity $(55 \pm 5 \%)$, maintained on a $12-\mathrm{h}$ light/dark cycle, and were given free access to water and food. The mice (5-6 weeks-old) were subcutaneously inoculated into the root region of the right hind leg with $6 \times 10^{6} \mathrm{U} 251$ cells (suspended in PBS) overexpressed with miR-218 or control cells to establish tumor xenografts. From day 3 post-injection, the formula, width ${ }^{2} \mathrm{x}$ length $\mathrm{x} 0.5$, was used to calculate tumor volumes every 2 days. After 13 days, the mice were sacrificed via cervical dislocation and tumors were harvested according to the National Institutes of Health (NIH) Guidelines. The maximum tumor size was $227.3 \mathrm{~mm}^{3}$. All animal experiments were approved by The Laboratory Animal Center of Xi'an Jiaotong University (Xi'an, China).

Immunohistochemistry (IHC). IHC analysis was performed as previously described (29) to detect Ki67 expression in the xenograft tumors, which were fixed in $4 \%$ paraformaldehyde at room temperature for $72 \mathrm{~h}$. Briefly, after dewaxing in xylene and rehydrating in a gradient concentration of ethanol, the paraffin-embedded tissue slides (with a thickness of $5 \mu \mathrm{m}$ ) were incubated in $0.3 \%$ hydrogen peroxide in distilled water at room temperature for $10 \mathrm{~min}$ to block endogenous peroxidase activity, then treated with an antigen retrieval method by heating, and were then incubated with mouse anti-Ki67 antibody (1:200; cat. no. 556003; BD Biosciences) overnight 
at $4^{\circ} \mathrm{C}$. Subsequently, the slides were incubated with biotinylated goat anti-mouse $\operatorname{IgG}(1: 3,000$; cat. no. TA130009; OriGene Technologies, Inc.) at $37^{\circ} \mathrm{C}$ for $1 \mathrm{~h}$. Immunodetection was performed with the Streptavidin-Peroxidase system (ZSGB-BIO; OriGene Technologies, Inc.) according to the manufacturer's protocol. After washing, diaminobenzidine and hematoxylin were respectively added at room temperature for $\sim 20 \mathrm{sec}$ to detect immunoreactive proteins. Ki67 protein expression was scored using a light microscope (magnification, x400; Olympus Corporation) in 5 random fields, in double-blinded way (i.e., without knowing the group of the case), and 0,1,2,3 represents negative, weak positive, positive and strong positive, respectively.

Statistical analysis. Statistical analysis was performed using SPSS 11.5 software (SPSS, Inc.). Continuous variables with normal distribution were analyzed by independent t-test (expressed as the means $\pm \mathrm{SD}$ ). A one-way analysis of variance (ANOVA) with Tukey's post hoc test was performed to test for the statistical significance of each quantified nuclear feature amongst the three groups in analyzing the effect of TGF $\beta$ and miR-218 on AP-1 signaling activity. $\mathrm{P}<0.05$ was considered to indicate a statistically significant difference.

\section{Results}

miR-218 expression is frequently downregulated in gliomas. To investigate miR-218 function in glioma tumorigenesis, miR-218-1 and miR-218-2 expression was analyzed in gliomas and normal brain tissues (control subjects) using a dataset from TCGA. As presented in Fig. 1A, both miR-218-1 and miR-218-2 expression levels were significantly downregulated in gliomas compared with the control subjects. In addition, miR-218-2 expression was significantly higher than miR-218-1 expression in gliomas $(4.99 \pm 1.95$ vs. $0.25 \pm 0.43$; $\mathrm{P}<0.001)$, indicating that mature miR-218 in gliomas is mostly constituted by miR-218-2, which was consistent with a previous study in thyroid cancers (30). miR-218-1 and miR-218-2 expression in gliomas was further analyzed with different histological grades. As revealed in Fig. 1B (left panel), miR-218-1 expression levels were not significantly different between gliomas with histological grade 2 (G2) and grade 3 (G3) $(\mathrm{P}=0.71)$. However, the gliomas with histological G3 had significantly lower miR-218-2 expression than those with histological G2 ( $\mathrm{P}=0.002$; Fig. 1B, right panel).

A large cohort of gliomas in TCGA dataset was analyzed via the Kaplan-Meier method. As revealed in Fig. 1C, the expression levels of miR-218-1 and miR-218-2 did not affect the survival of patients with glioma when their survival time was $<2,000$ days. However, miR-218-2 downregulation but not that of miR-218-1 was significantly associated with poor patient survival when their survival time was $>2,000$ days (Fig. 1D). Collectively, these results indicated that miR-218-2 may be a potential biomarker to predict long-term survival of patients with glioma.

miR-218 inhibits glioma cell proliferation. To determine the biological function of miR-218 in glioma, a series of in vitro experiments with miR-218 gain-of-function in glioma cells were performed using miR-218 mimics and NC mimics (Fig. 2A). The results demonstrated that miR-218 mimics significantly suppressed the proliferation of U251 and SHG44 cells compared with the controls (Fig. 2B). The effect of miR-218 mimics on cell proliferation using soft agar colony formation assay was also assessed. The colonies were divided into different groups by size. The results demonstrated that fewer cell colonies were formed following overexpression of miR-218 compared with the control cells in the large size group (area of colonies $\geq 3,000 \mu \mathrm{m}^{2}$ ) (Fig. 2C). However, the number of colonies was not significantly different between overexpression of miR-218 cells and control cells in the small size group (area of colonies $<3,000 \mu \mathrm{m}^{2}$ ) (Fig. 2C). The in vivo tumor-suppressing effect of miR-218 was also evaluated in nude mice. Lentivirus encoding miR-218 and control lentivirus were transfected into cells to establish tumor xenografts. These lentiviruses were only used in the nude mice tumorigenesis experiment. miR-218 expression was confirmed after harvesting the tumor tissue (Fig. 2D). It was revealed that U251 cells stably expressing miR-218 induced tumors which had significantly smaller mean tumor volumes and longer latency compared with the control (Fig. 2E). The xenograft tumors were isolated and weighed at the end of the experiments. As presented in Fig. 2F, tumors stably expressing miR-218 weighed significantly less than the control tumors $(\mathrm{P}=0.0009)$. As anticipated, the percentage of Ki67-positive cells was significantly lower in cells stably expressing miR-218 (Fig. 2G).

The effects of miR-218 mimics on cell cycle distribution and apoptosis in U251 and SHG44 cells were assessed. The results demonstrated that the cell cycle of miR-218-overexpressing cells was arrested at the $G_{0} / G_{1}$ phase compared with the control cells (Fig. 3A). The percentage of cells in the $G_{0} / G_{1}$ phase increased from $51.7 \pm 2.4$ to $62.3 \pm 2.0 \%$ in U251 cells $(\mathrm{P}=0.004)$ and from $52.3 \pm 2.7$ to $66.6 \pm 3.7 \%$ in $\mathrm{SHG} 44$ cells $(\mathrm{P}=0.005)$. In addition, transfection with miR-218 mimics increased both early and late apoptosis compared with the control $(20.5 \pm 1.1$ vs. $28.9 \pm 1.8 \%$ in U251 cells, $\mathrm{P}<0.002$; and $7.2 \pm 1.3$ vs. $16.0 \pm 2.1 \%$ in SHG44 cells, $\mathrm{P}=0.003$; Fig. $3 \mathrm{~B}$ ). Collectively, these results indicated that miR-218 acts as a tumor suppressor in glioma cells.

miR-218 inhibits glioma cell migration and invasion. The effect of miR-218 mimics on migration and invasion potential was assessed in U251 and SHG44 cells. The results demonstrated that overexpression of miR-218 significantly suppressed the migration in U251 and SHG44 cells (Fig. 4). In addition, transfection with miR-218 mimics significantly downregulated the ability of cells to invade through the Matrigel-coated membrane (Fig. 4). Collectively, these results indicated that miR-218 is closely associated with metastatic phenotypes of glioma cells.

$T N C$ is a novel target of miR-218. A panel of candidate genes, which are potentially targeted by miR-218, were identified using target predicting tools, such as miRanda, TargetScan and miRDB. Among them, genes involved in vital signaling pathways were selected, including inhibitor of $\mathrm{NF}-\kappa \mathrm{B}$ kinase subunit $\beta(I K B K B), T N C$ and $W N T 2 B$. As revealed in Fig. 5A and B, and Fig. S1, only TNC was notably downregulated following transfection with miR-218 mimics in these two 

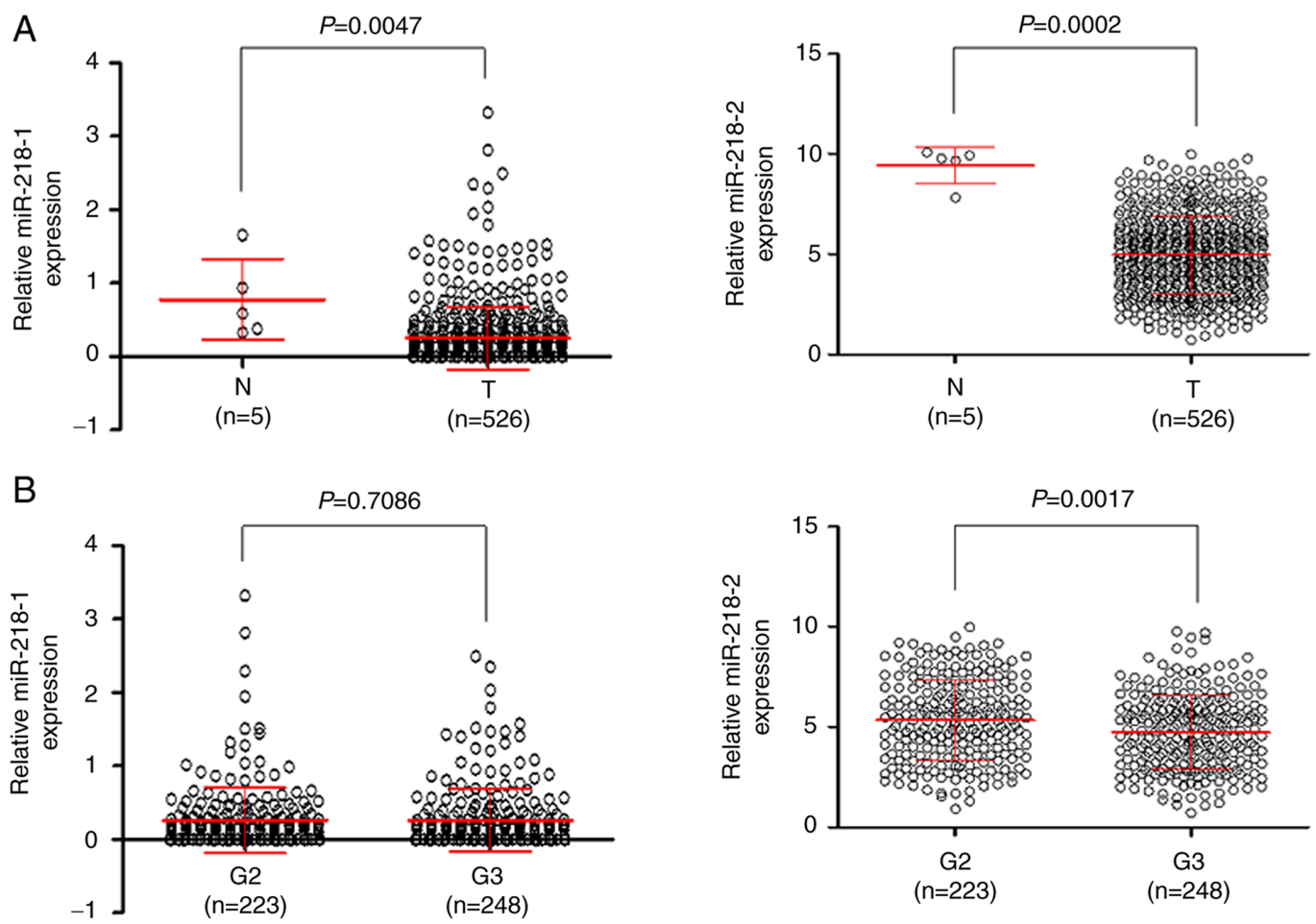

C
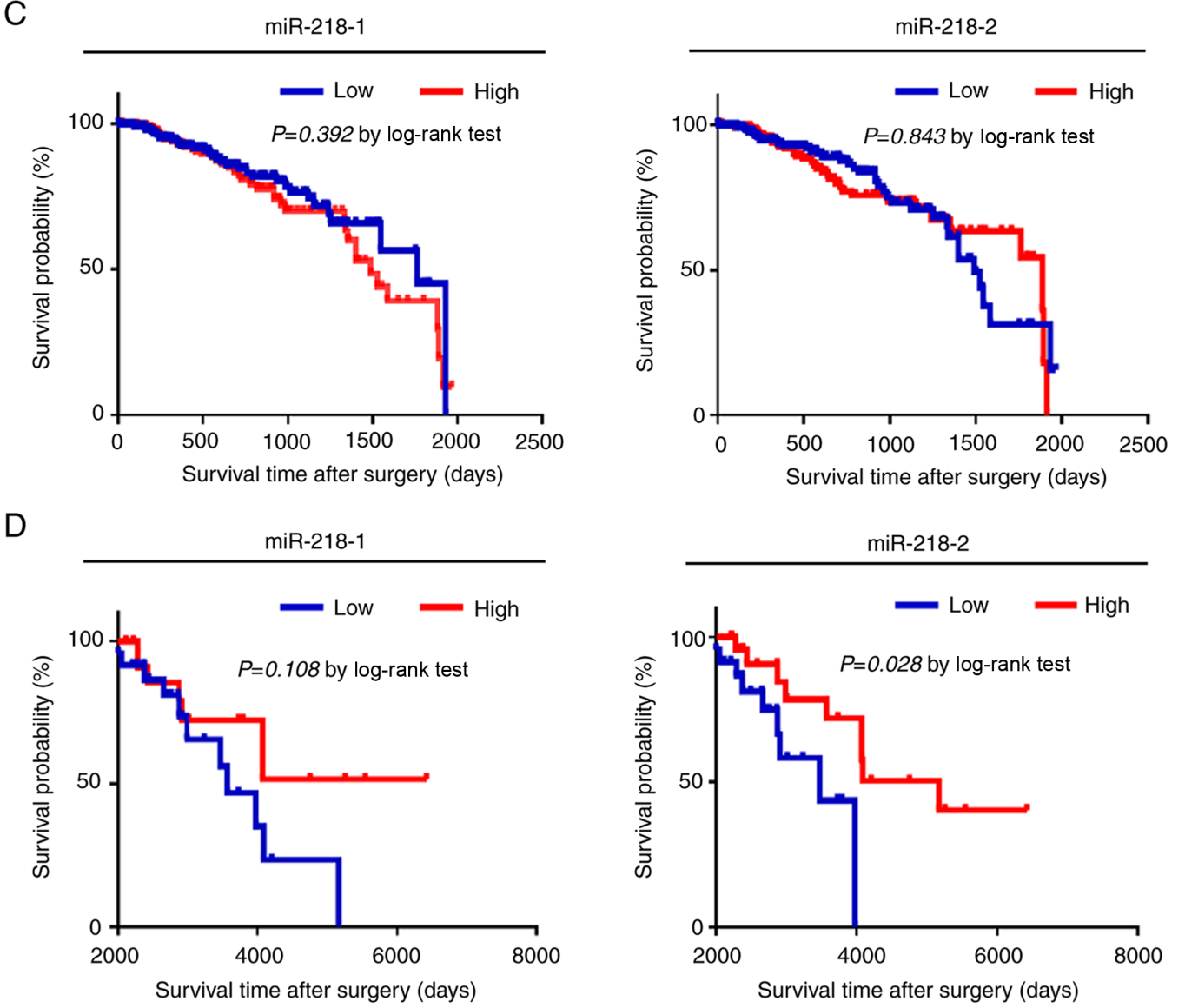

Figure 1. Downregulation of miR-218 in gliomas. (A) Expression of miR-218-1 and miR-218-2 in a panel of gliomas (T) and normal brain tissues (N). (B) The expression of miR-218-1 and miR-218-2 in gliomas with different histologic grades. (C) The association of miR-218-1/2 expression with short-term survival $(<2,000$ days) of glioma patients. (D) The association of miR-218-1/2 expression with long-term survival ( $>2,000$ days) of glioma patients. The data were obtained from The Cancer Genome Atlas database and were expressed as the mean \pm SD. miR, microRNA.

cell lines, at both the mRNA and protein levels. In addition, miR-218 modulated TNC via a direct interaction. A total of two
TNC 3'-UTR (attached to luciferase coding region) luciferase reporter plasmids, which contained putative miR-218 binding 
A

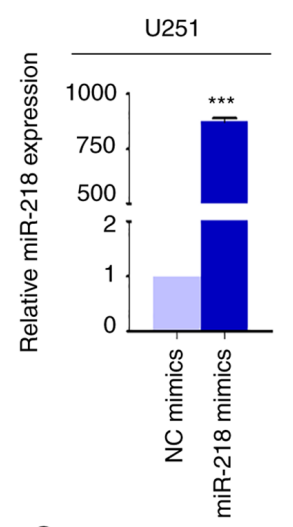

C
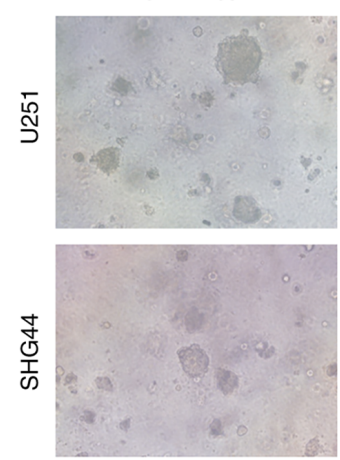

D

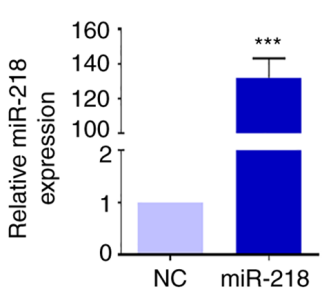

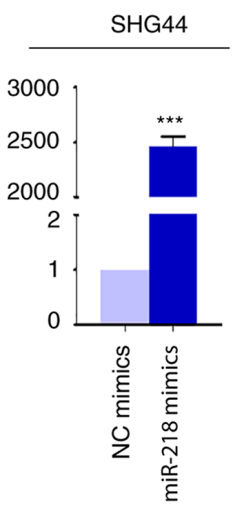

miR-218 mimics
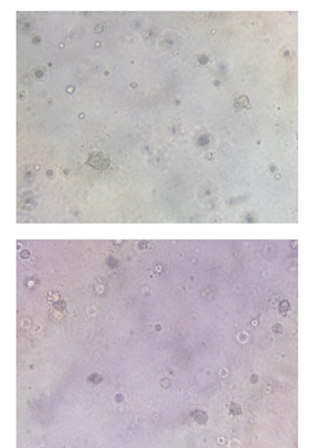

E
B

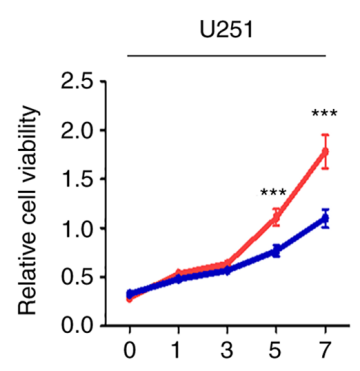

miR-218 mimics

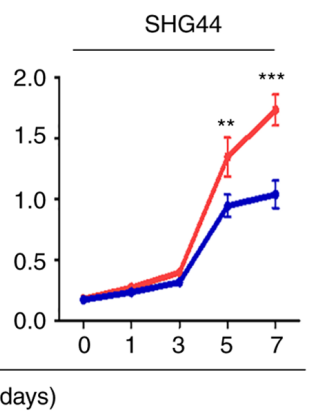

miR-218 mimics
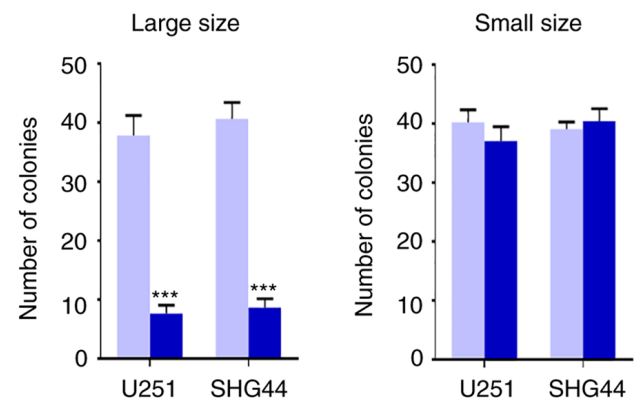

\section{G}
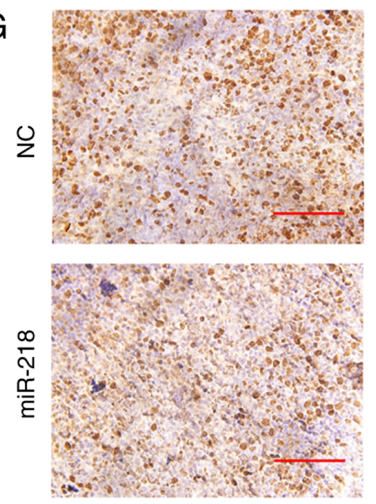

$\mathrm{F}$
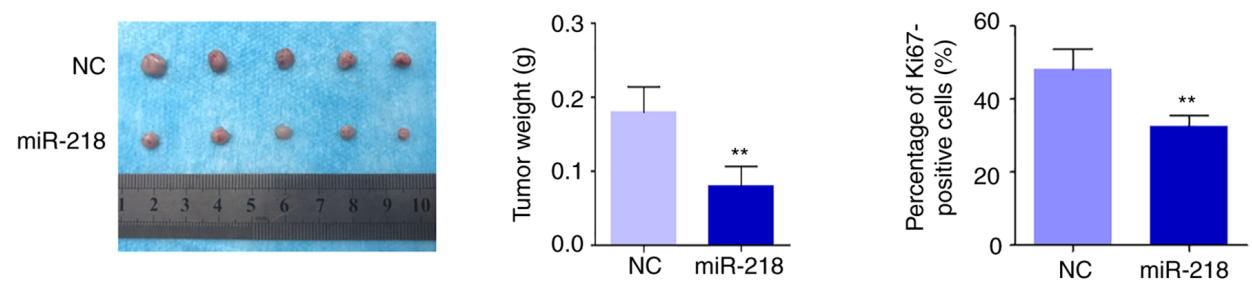

Figure 2. Inhibitory effect of miR-218 on glioma cell growth. (A) U251 and SHG44 cells were transfected with miR-218 mimics and the negative control (NC) mimics, and reverse transcription-quantitative PCR was performed to monitor miR-218 expression. U6 was used as a reference gene. (B) The MTT assay was used to evaluate the inhibitory effect of miR-218 mimics on the proliferation of the indicated glioma cells. (C) The effect of miR-218 mimics on colony formation ability of the indicated glioma cells. Left panels demonstrated the representative images of colony formation, and right panels represented quantitative analysis of colony numbers. (D) Lentivirus encoding miR-218 and control lentivirus were transfected into cells to establish tumor xenografts. Those lentiviruses were only used in nude mice tumorigenesis experiment. miR-218 expression was confirmed after harvesting the tumor tissue. (E) Tumor growth curves were compared between U251 cells stably expressing miR-218 and control cells in nude mice ( $\mathrm{n}=5 /$ group). Tumor cells were injected at day 0 . (F) Images (left panel) and histogram of tumor weight (right panel) of dissected tumors from miR-218-overexpression and control groups. (G) Representative Ki67 staining of dissected tumors from the indicated groups was revealed in upper panel. The histogram (lower panel) represents the percentage of Ki67-positive cells from 5 microscopic fields in each group (magnification, $\mathrm{x} 400$; upper panel). Scale bars, $200 \mu \mathrm{m}$. The data are expressed as the mean $\pm \mathrm{SD}$. ${ }^{*} \mathrm{P}<0.05$, ${ }^{* *} \mathrm{P}<0.01$ and ${ }^{* * *} \mathrm{P}<0.001 . \mathrm{miR}$, microRNA; NC, negative control.

sites, WT 5'-AAGCACA-3' and MUT 5'-ACGAATA-3', were constructed (Fig. 5C). The results demonstrated that luciferase activity was significantly suppressed by miR-218 mimics in U251 and SHG44 cells transfected with WT luciferase reporter plasmid (Fig. 5D). Notably, luciferase activity remained unchanged in cells transfected with MUT luciferase 
A
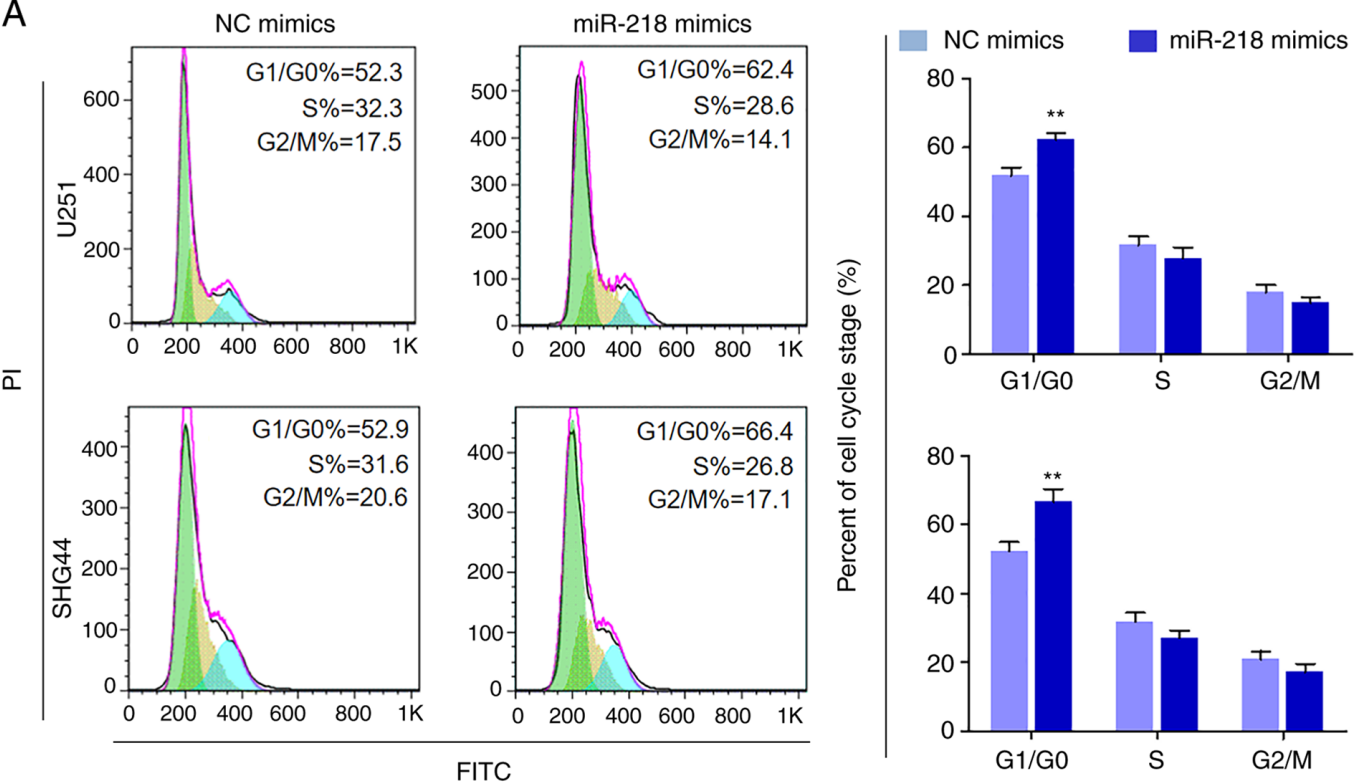

B
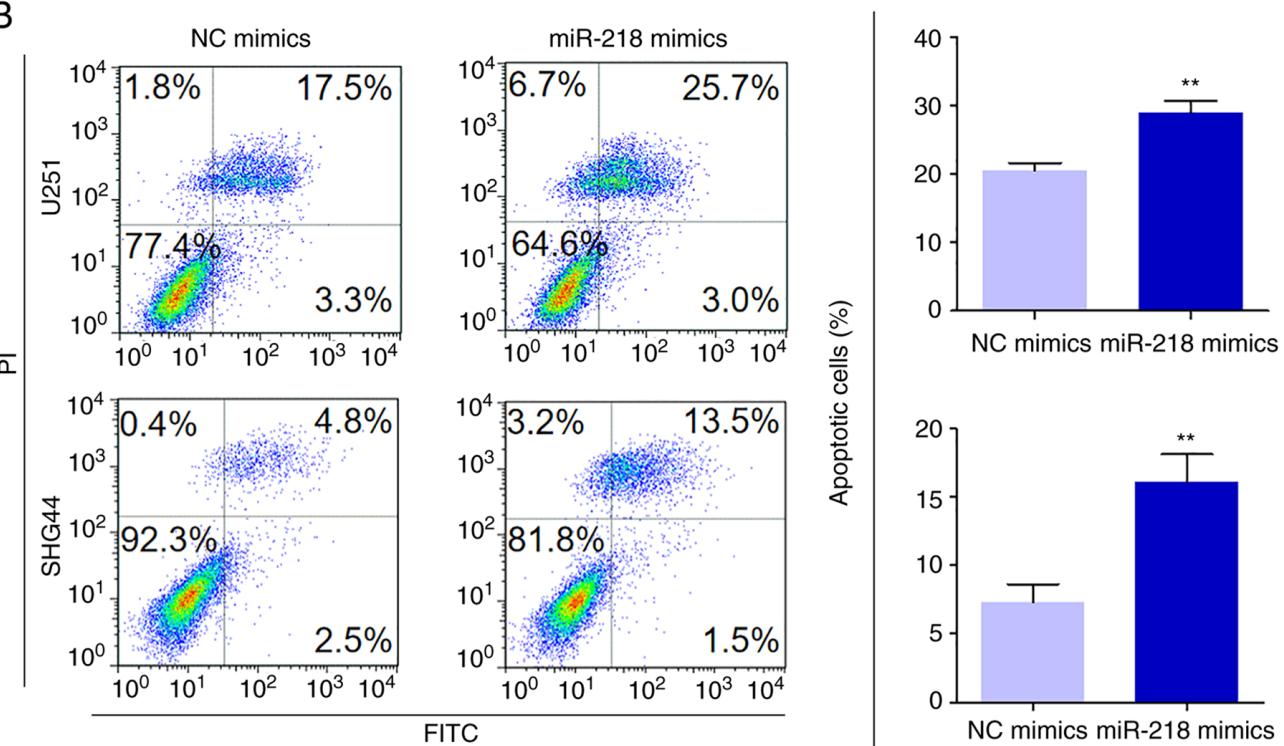

Figure 3. Induction of cell arrest and apoptosis by miR-218 in glioma cells. U251 and SHG44 cells were transiently transfected with miR-218 and NC mimics. (A) Cell cycle distributions and (B) apoptosis were then analyzed by flow cytometry. Representative flow cytometric analyses of cell cycle and apoptosis were presented in the left panels. Quantitative analyses of cell cycle fractions and cell apoptosis were presented in the right panels. The data are expressed as the mean $\pm \mathrm{SD} .{ }^{* *} \mathrm{P}<0.01 . \mathrm{miR}$, microRNA; NC, negative control.

reporter plasmid (Fig. 5D). Collectively, these results indicated that $T N C$ is a direct target of miR-218.

TNC expression was analyzed in gliomas and normal brain tissues using a dataset from TCGA. The results demonstrated that $T N C$ expression was significantly upregulated in gliomas (Fig. 5E), which was consistent with a previous study (24). In addition, the correlation between miR-218-1/miR-218-2 and $T N C$ expression in gliomas was also investigated. As revealed in Fig. 5F, TNC expression was significantly correlated with miR-218-1 expression $(\mathrm{P}=0.024, \mathrm{r}=-0.10$; Pearson's correlation coefficient, left panel), and was significantly correlated with miR-218-2 expression $(\mathrm{P}<0.0001, \mathrm{r}=-0.26$; Pearson's correlation coefficient, right panel).

miR-218 functions as a tumor suppressor in glioma cells by inhibiting the TNC/AKT/AP-1/TGFB1-positive feedback loop. The molecular mechanism of malignant phenotypes of glioma cells inhibited by miR-218 was investigated. Increasing evidence has indicated that TNC can increase phosphorylation of AKT at Ser473 by interacting with integrins, thereby activating the PI3K/AKT pathway (31-33). Thus, it was hypothesized that miR-218 may inhibit the PI3K/AKT signaling by targeting TNC. The results demonstrated that transfection with miR-218 mimics downregulated TNC expression, and notably inhibited phosphorylation of AKT at Ser473, while it slightly affected phosphorylation of AKT at Thr308 in U251 and SHG44 cells (Fig. 6A).

Targeted by the PI3K/AKT signaling pathway, transcription factor AP-1 is constitutively activated in glioma and is important in cell proliferation (34-37). AP-1, which can bind to a common DNA binding sequence, is a heterodimer composed primarily by the FOS and JUN families $(38,39)$. AP-1 activation 

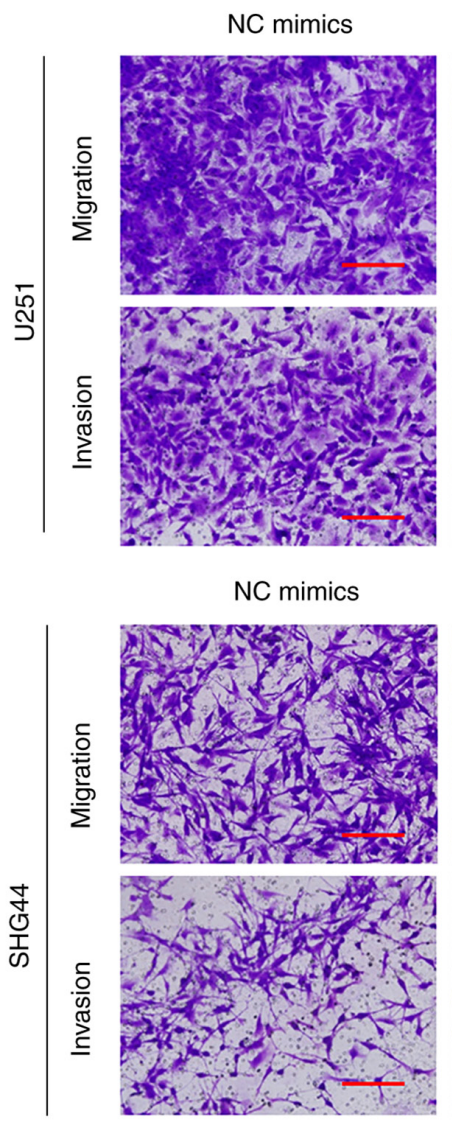

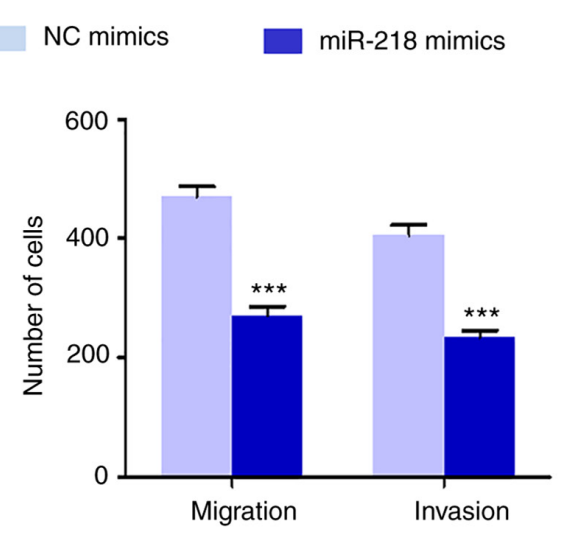

miR-218 mimics
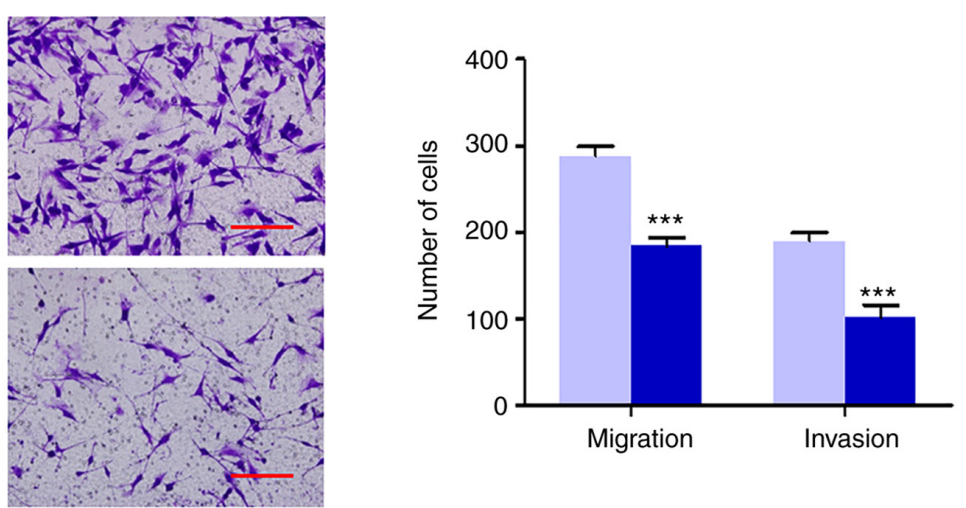

Figure 4. Inhibitory effect of miR-218 on glioma cell migration and invasion. U251 and SHG44 cells were transiently transfected with miR-218 and NC mimics. The representative images of migratory/invasive U251/SHG44 cells were revealed in the left panels, and statistical data of cell numbers were revealed in the right panels. The data are expressed as the mean $\pm \mathrm{SD}$. Scale bars, $50 \mu \mathrm{m} .{ }^{* * *} \mathrm{P}<0.001$. miR, microRNA; NC, negative control.

involves complex processes, such as increased expression or phosphorylation of FOS and JUN (40). As revealed in Fig. 6A, transfection with miR-218 mimics markedly inhibited JNK phosphorylation, while it slightly affected FOS, JUN and total JNK expression in U251 and SHG44 cells. Considering that TGF $\beta 1$ is a well-known target of AP-1 (41-43), it was hypothesized that miR-218 could downregulate TGF $\beta 1$ expression by suppressing AP-1 activity. As revealed in Fig. 6A, transfection with miR-218 mimics decreased TGF $\beta 1$ expression in U251 and SHG44 cells compared with the control. Collectively, these results indicated that transcriptional activity of AP-1 could be inhibited by miR-218, as supported by the AP-1 luciferase reporter assay (Fig. 6B).

To confirm the in vivo findings, western blot analysis was performed to detect the indicated gene expression in the xenograft tumors. The results demonstrated that TNC expression was significantly decreased in tumors overexpressing miR-218 (transfected with lentivirus encoding miR-218) compared with control tumors (transfected with control lentivirus) (Fig. 6C). As anticipated, phosphorylation of AKT at Ser473, p-JNK and TGF $\beta 1$ expression was markedly decreased in tumors overexpressing miR-218 compared with the control tumors. However, no significant differences were observed in phosphorylation of AKT at Thr308 and the expression levels of FOS, JUN and total JNK between the two groups, further supporting the in vitro findings. Notably, TGF $\beta 1$ has been reported to induce TNC expression involving Smad3/4, Sp1 transcription factor, ETS proto-oncogene 1, transcription factor and CBP300 (44).
Thus, it was hypothesized that TGF $\beta 1$ could activate the AKT/AP-1 signaling axis by upregulating TNC expression, thereby forming a positive feedback loop. To demonstrate this, U251 and SHG44 cells were treated with recombinant human TGF $\beta 1$ proteins. The results demonstrated that treatment with TGF $\beta 1$ markedly induced TNC expression and subsequently increased phosphorylation of AKT at Ser473 and JNK expression, the effects of which were reversed following transfection with miR-218 mimics (Fig. 6D). This was also supported by the AP-1 luciferase reporter assay (Fig. 6E). Collectively, these results indicated that miR-218 acts as a tumor suppressor in glioma cells by blocking the TNC/AKT/AP-1/TGF $\beta 1$-positive feedback loop.

In the present study, a model was proposed to investigate the molecular mechanism of miR-218 inhibiting malignant progression of glioma (Fig. 6F). Briefly, miR-218 suppresses TNC expression by binding to its 3 '-UTR. This in turn decreases AKT phosphorylation and subsequently suppresses transcriptional activity of AP-1 by decreasing JNK phosphorylation, thereby downregulating TGF $\beta 1$ expression, which activates the TNC/AKT/AP-1 signaling axis. Thus, miR-218 acts as a potent tumor suppressor in glioma by blocking the TNC/AKT/AP-1/TGFß1-positive feedback loop.

\section{Discussion}

miR-218 has been widely reported to act as a putative tumor suppressor that is downregulated in several types of human 
A

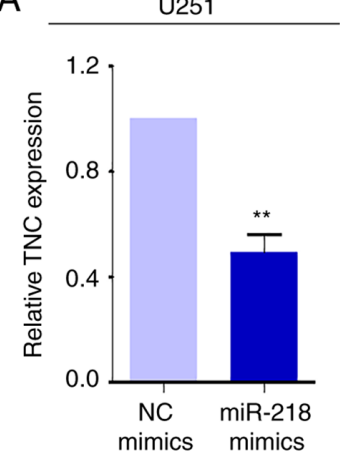

SHG44

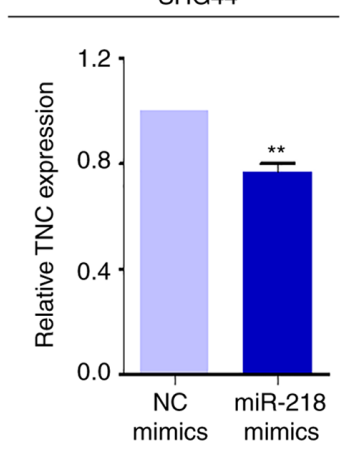

B
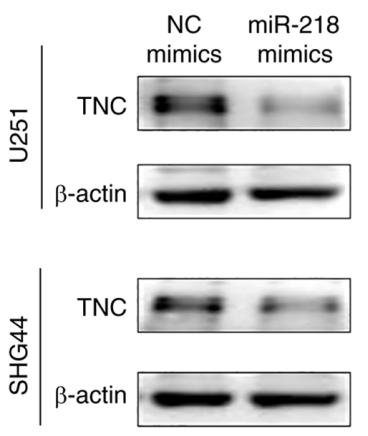

C

miR-218 UGUACCAAUCUAGUUCGUGUU

TNC 3'UTR WT

\|\|\|\|

TNC 3'UTR MUT $\quad$...TTTTTTAAATAAACGAATAAGTACTTTTGTTA...
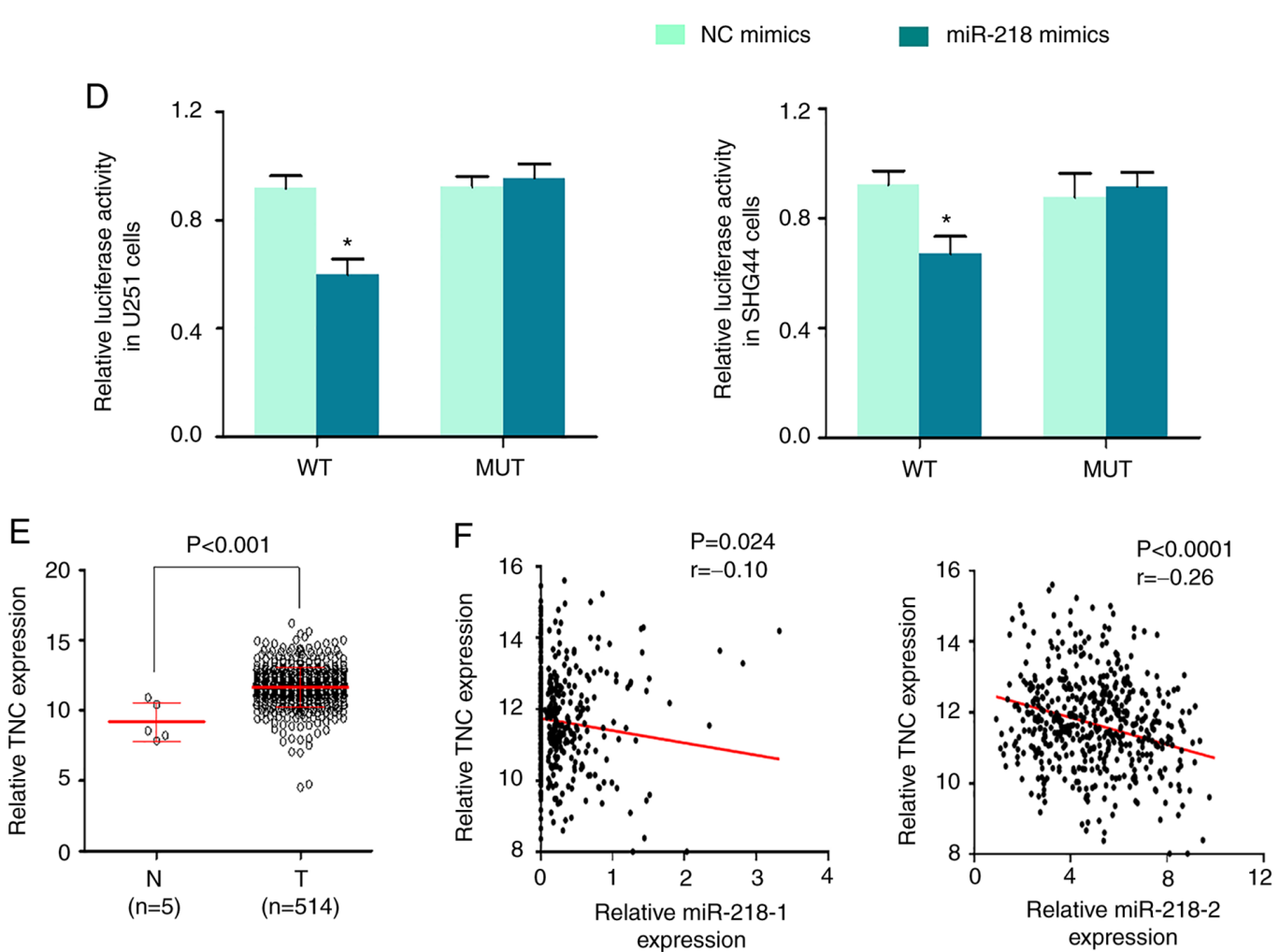

Figure 5. Identification of TNC as a target of miR-218. The effect of miR-218 on TNC expression in U251 and SHG44 cells was assessed by (A) reverse transcription-quantitative PCR and (B) western blot assays. (C) Sequence of the TNC 3'-UTR revealing miR-218 binding sites. Matching regions were highlighted by lines. WT and MUT (red bases indicating mutation sites) TNC 3'-UTR fragments were revealed. (D) The indicated cells were co-transfected with miR-218 mimics/NC mimics and WT/MUT luciferase reporter plasmids, and luciferase activity was then analyzed in these cells with empty vector as the control. Transfection efficiency was normalized by measuring Renilla luciferase. (E) TNC expression in a panel of gliomas (T) and normal brain tissues (N) (data from The Cancer Genome Atlas database). (F) The association of TNC expression with the expression of miR-218-1 (left panel) and miR-218-2 (right panel) in gliomas was assessed by linear regression analysis. The data were expressed as the mean $\pm \mathrm{SD}$. ${ }^{*} \mathrm{P}<0.05$ and ${ }^{* *} \mathrm{P}<0.01$. TNC, tenascin C; miR, microRNA; UTR, untranslated region; MUT, mutant; WT, wild-type; NC, negative control.

cancer, including gastric, nasopharyngeal, lung, cervical, oral and brain tumors (14-16,45-49). Low miR-218 expression is closely associated with poor overall survival and disease-free survival in patients with glioma (17). However, the role and underlying molecular mechanism of miR-218 in glioma remains unclear.

The results of the present study demonstrated that miR-218 acted as a potent tumor suppressor in glioma.
TCGA dataset was systematically analyzed, and the results demonstrated that both miR-218-1 and miR-218-2 expression levels were significantly downregulated in gliomas compared with the control subjects. In addition, the results confirmed that miR-218-2 constituted most of the mature miR-218 in gliomas. miR-218-2 expression was negatively correlated with histological grading of patients with gliomas. Notably, downregulated miR-218-2 expression 
A

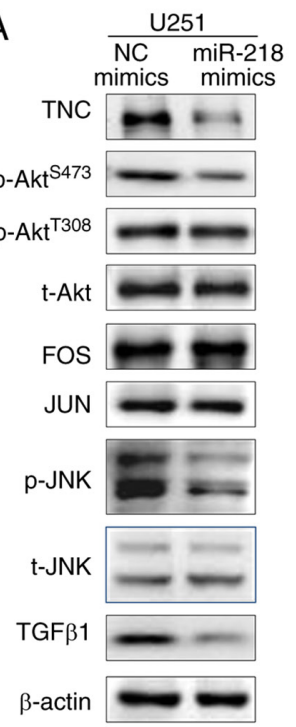

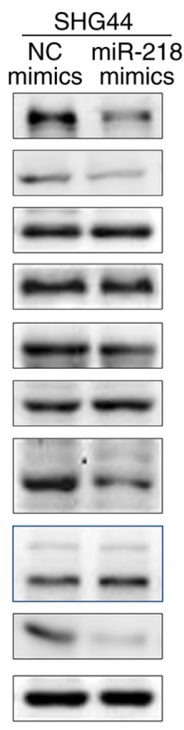

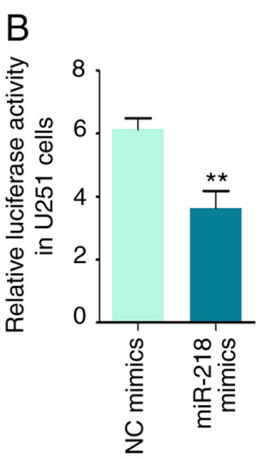

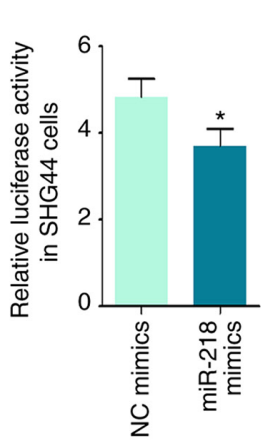

D

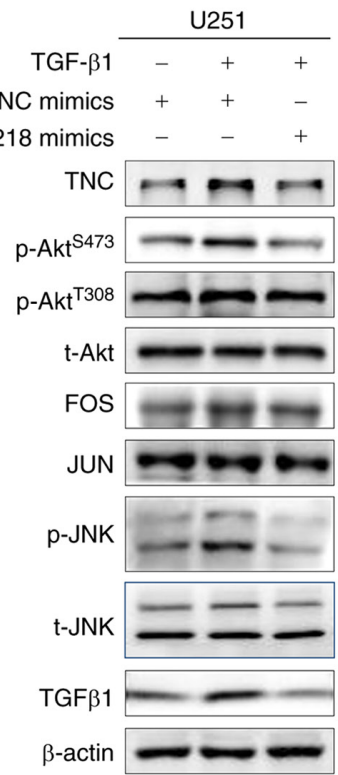

E

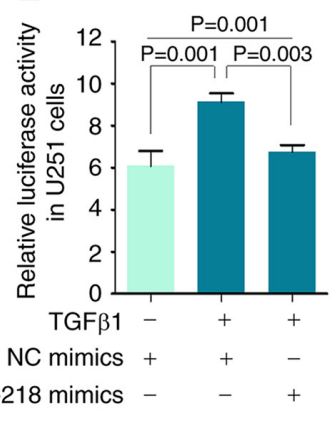

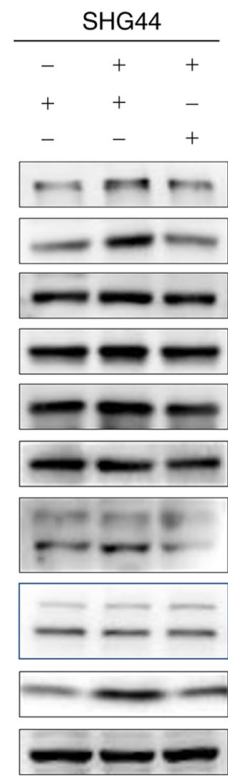

$P=0.001$

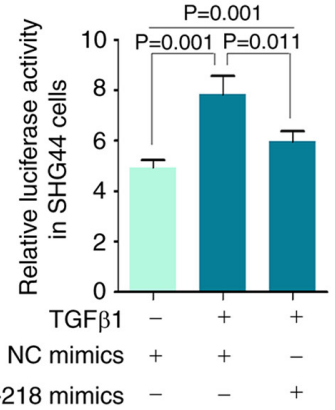

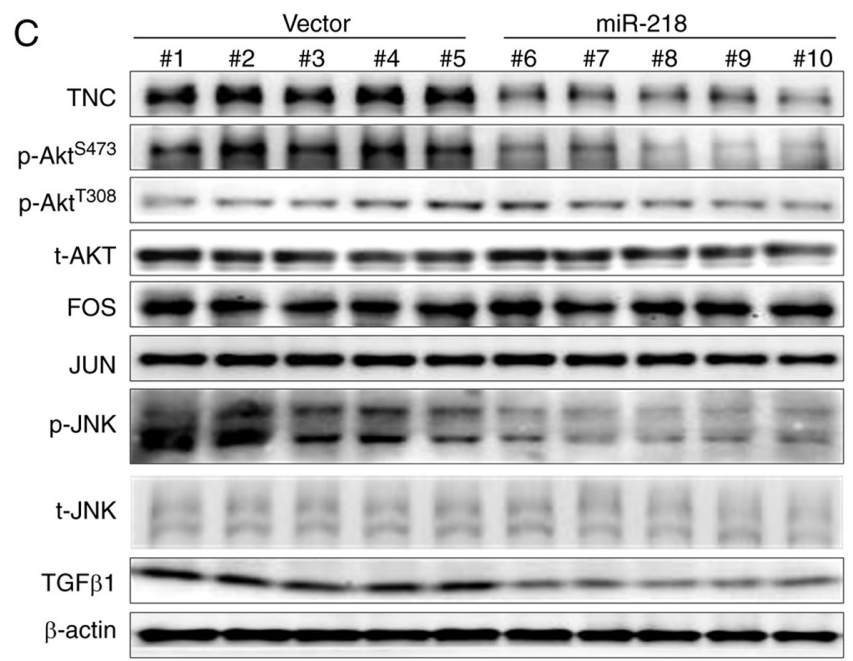

$\mathrm{F}$

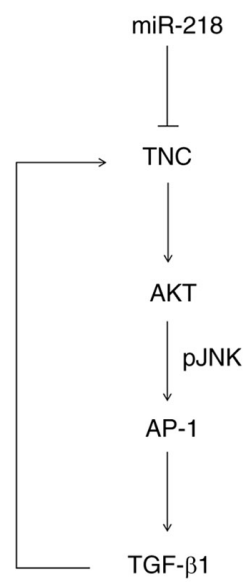

Figure 6. Blockade of the TNC/AKT/AP-1/TGFß1-positive feedback loop by miR-218. (A) The effect of miR-218 mimics on the expression or phosphorylation of the indicated proteins in U251 and SHG44 cells was assessed by western blot analysis. $\beta$-actin was used as a loading control. (B) Dual-luciferase reporter system was used to assess the effect of miR-218 mimics on AP-1 activity in U251 and SHG44 cells. Empty vector was used as the control. The ratio of the Luc/Renilla activity was presented as the mean \pm SD of three independent assays. (C) Lentivirus-encoding miR-218 and control lentivirus were transfected into cells to establish tumor xenografts. The effect of miR-218 on the expression or phosphorylation of the indicated proteins in the xenograft tumors was evaluated by western blot analysis. (D) U251 and SHG44 cells transfected with miR-218 or NC mimics were treated with or without exogenous TGF $\beta 1$. Western blot analysis was performed to detect the expression or phosphorylation of the indicated proteins. $\beta$-actin was used as a loading control. (E) Dual-luciferase reporter system was performed to assess AP-1 activity. Empty vector was used as the control. The ratio of the Luc/Renilla activity was expressed as the mean \pm SD. (F) A schematic model illustrating the mechanism of miR-218 inhibiting malignant phenotypes of glioma cells. " $\mathrm{P}<0.05$ and ${ }^{* *} \mathrm{P}<0.01$. miR, microRNA; TNC, tenascin C; TGF $\beta 1$, transforming growth factor $\beta 1$; AP-1, activator protein 1; Luc, luciferase; NC, negative control.

was closely associated with poor long-term survival of patients with glioma. Collectively, these results indicated that miR-218-2 may be a potential prognostic biomarker for patients with glioma. Furthermore, transfection with miR-218 mimics significantly suppressed the malignant phenotypes of glioma cells, which validated the tumor 
suppressive role of miR-218 in glioma cells, which was consistent with a previous study (50).

To further understand the tumor suppressive role of miR-218 in gliomas, TNC was identified as a novel target of miR-218 using target prediction tools, western blotting and the dual-luciferase reporter assay. Analysis of TCGA dataset demonstrated that TNC expression was significantly increased in gliomas compared with the control subjects, and was negatively correlated with miR-218 expression, particularly miR-218-2. TNC, which is characterized by a modular construction and a six-armed quaternary structure, is a large secreted oligomeric extracellular matrix glycoprotein that binds to integrin cell adhesion receptors, periostin, syndecan membrane proteoglycans and fibronectin (51-53). In the present study, transfection with miR-218 mimics downregulated TNC mRNA and protein expression levels, both in vitro and in vivo.

TNC has been reported to activate the PI3K/AKT signaling pathway by interacting with integrins (31-33). Thus, the present study assessed the effect of miR-218 on PI3K/AKT pathway activity. The results demonstrated that transfection with miR-218 mimics markedly inhibited phosphorylation of AKT at Ser473, but not at Thr308, in glioma cells. Furthermore, transcriptional activity of AP-1, a downstream target of the PI3K/AKT pathway (34-37), was markedly inhibited by miR-218 by decreasing JNK phosphorylation. Considering that AP-1 transcriptionally induces TGF $\beta 1$ by binding to its promoter region (41-43), it was hypothesized that miR-218 may downregulate TGF $\beta 1$ expression by suppressing AP-1 activity through blocking PI3K/AKT signaling. The results confirmed that miR-218 mimics markedly decreased TGF $\beta 1$ expression in both glioma cell lines and xenograft tumors, accompanied by decreased TNC expression and inhibition of AKT/JNK phosphorylation.

TGF $\beta 1$ has been reported to induce TNC expression $(44,54)$. Thus, it was hypothesized that TGF $\beta 1$ can form a positive feedback loop with the TNC/AKT/AP-1 signaling axis. The results demonstrated that exogenous TGF $\beta 1$ notably increased TNC expression and subsequently enhanced phosphorylation of AKT at Ser473 and AP-1 activity, the effects of which were reversed following transfection with miR-218 mimics.

In conclusion, the results of the present study indicated that miR-218 acts as a tumor suppressor in glioma. Furthermore, TNC was identified as a novel target of miR-218. Notably, miR-218 inhibited the malignant phenotypes of glioma cells by blocking the TNC/AKT/AP-1/TGF 31 -positive feedback loop.

\section{Acknowledgements}

Not applicable.

\section{Funding}

The present study was supported by the National Natural Science Foundation of China (grant no. 81572697).

\section{Availability of data and materials}

All data generated or analyzed during this study are included in this published article.

\section{Authors' contributions}

MJ and GL conceived and designed the experiments. SD, RZ and ST conducted the experiments. SD, PH and MJ analyzed the data. GL and MJ contributed to acquisition of reagents and materials. SD and PH wrote the manuscript. SD and PH confirm the authenticity of all the raw data. All authors read and approved the final manuscript.

\section{Ethics approval and consent to participate}

All animal experiments were approved by The Laboratory Animal Center of Xi'an Jiaotong University (Xi'an, China).

\section{Patient consent for publication}

Not applicable.

\section{Competing interests}

The authors declare that they have no competing interests.

\section{References}

1. Jemal A, Bray F, Center MM, Ferlay J, Ward E and Forman D: Global cancer statistics. CA Cancer J Clin 61: 69-90, 2011.

2. Clarke J, Butowski N and Chang S: Recent advances in therapy for glioblastoma. Arch Neurol 67: 279-283, 2010.

3. Park DM, Sathornsumetee S, Rich JN: Medical oncology: Treatment and management of malignant gliomas. Nat Rev Clin Oncol 7: 75-77, 2010.

4. Castro MG, Candolfi M, Kroeger K, King GD, Curtin JF, Yagiz K, Mineharu Y, Assi H, Wibowo M, Ghulam Muhammad AK, et al: Gene therapy and targeted toxins for glioma. Curr Gene Ther 11: 155-180, 2011.

5. Hu J, Sun T, Wang H, Chen Z, Wang S, Yuan L, Liu T, Li HR, Wang P, Feng Y, et al: MiR-215 is induced post-transcriptionally via HIF-Drosha complex and mediates glioma-Initiating cell adaptation to hypoxia by targeting KDM1B. Cancer Cell 29: 49-60, 2016.

6. Dang SW, Zhou JS, Chen YJ, Chen P, Ji MJ, Shi BY, Yang Q and Hou P: Dynamic expression of ZNF382 and its tumor-suppressor role in hepatitis B virus-related hepatocellular carcinogenesis. Oncogene 38: 4804-4819, 2019.

7. Bartel DP: MicroRNAs: Genomics, biogenesis, mechanism, and function. Cell 116: 281-297, 2004.

8. Chen X, Zhang X, Sun S and Zhu M: MicroRNA-432 inhibits the aggressiveness of glioblastoma multiforme by directly targeting IGF-1R. Int J Mol Med 45: 597-606, 2020.

9. Liu FZ, Lou K, Zhao XT, Zhang J, Chen W, Qian YC, Zhao YB, Zhu Y and Zhang Y: miR-214 regulates papillary thyroid carcinoma cell proliferation and metastasis by targeting PSMD10. Int J Mol Med 42: 3027-3036, 2018.

10. Park S and James CD: ECop (EGFR-coamplified and overexpressed protein), a novel protein, regulates NF-kappaB transcriptional activity and associated apoptotic response in an IkappaBalpha-dependent manner. Oncogene 24: 2495-2502, 2005.

11. Frampton AE, Castellano L, Colombo T, Giovannetti E, Krell J, Jacob J, Pellegrino L, Roca-Alonso L, Funel N, Gall TM, et al: Integrated molecular analysis to investigate the role of microRNAs in pancreatic tumour growth and progression. Lancet 385 (Suppl 1): S37, 2015.

12. Dvinge H, Git A, Graf S, Salmon-Divon M, Curtis C, Sottoriva A, Zhao Y, Hirst M, Armisen J, Miska EA, et al: The shaping and functional consequences of the microRNA landscape in breast cancer. Nature 497: 378-382, 2013.

13. Ding PF, Liang B, Shou JX ane Wang WJ: lncRNA KCNQ1OT1 promotes proliferation and invasion of glioma cells by targeting the miR-375/YAP pathway. Int J Mol Med 46: 1983-1992, 2020.

14. Song L, Huang Q, Chen K, Liu L, Lin C, Dai T, Yu C, Wu Z and Li J: miR-218 inhibits the invasive ability of glioma cells by direct downregulation of IKK- $\beta$. Biochem Biophys Res Commun 402: $135-140,2010$. 
15. Setty M, Helmy K, Khan AA, Silber J, Arvey A, Neezen F, Agius P, Huse JT, Holland EC and Leslie CS: Inferring transcriptional and microRNA-mediated regulatory programs in glioblastoma. Mol Syst Biol 8: 605, 2012.

16. Xia H, Yan Y, Hu M, Wang Y, Wang Y, Dai Y, Chen J, Di G, Chen X and Jiang X: MiR-218 sensitizes glioma cells to apoptosis and inhibits tumorigenicity by regulating ECOP-mediated suppression of NF- $\kappa$ B activity. Neuro Oncol 15: 413-422, 2013

17. Cheng MW, Wang LL and Hu GY: Expression of microRNA-218 and its clinicopathological and prognostic significance in human glioma cases. Asian Pac J Cancer Prev 16: 1839-1843, 2015.

18. Luo Y, Hou WT, Zeng L, Li ZP, Ge W, Yi C, Kang JP, Li WM, Wang F, Wu DB, et al: Progress in the study of markers related to glioma prognosis. Eur Rev Med Pharmacol Sci 24: 7690-7697, 2020 .

19. Tatarano S, Chiyomaru T, Kawakami K, Enokida H, Yoshino H Hidaka H, Yamasaki T, Kawahara K, Nishiyama K, Seki N and Nakagawa M: miR-218 on the genomic loss region of chromosome $4 \mathrm{p} 15.31$ functions as a tumor suppressor in bladder cancer. Int J Oncol 39: 13-21, 2011.

20. Erickson HP: Tenascin-C, tenascin-R and tenascin-X: A family of talented proteins in search of functions. Curr Opin Cell Biol 5: 869-876, 1993.

21. Jones PL, Jones FS: Tenascin-C in development and disease: Gene regulation and cell function. Matrix Biol 19: 581-596, 2000

22. Fassler R, Sasaki T, Timpl R, Chu ML and Werner S: Differential regulation of fibulin, tenascin- $\mathrm{C}$, and nidogen expression during wound healing of normal and glucocorticoid-treated mice. Exp Cell Res 222: 111-116, 1996.

23. Zagzag D, Friedlander DR, Miller DC, Dosik J, Cangiarella J, Kostianovsky M, Cohen H, Grumet M and Greco MA: Tenascin expression in astrocytomas correlates with angiogenesis. Cancer Res 55: 907-914, 1995.

24. Zamecnik J: The extracellular space and matrix of gliomas. Acta Neuropathol 110: 435-442, 2005.

25. Rolle K, Nowak S, Wyszko E, Nowak M, Zukiel R, Piestrzeniewicz R, Gawronska I, Barciszewska MZ and Barciszewski J: Promising human brain tumors therapy with interference RNA intervention (iRNAi). Cancer Biol Ther 9: 396-406, 2010

26. Doecke JD, Wang Y and Baggerly K: Co-localized genomic regulation of miRNA and mRNA via DNA methylation affects survival in multiple tumor types. Cancer Genet 209: 463-473, 2016.

27. Shi J, Liu W, Sui F, Lu R, He Q, Yang Q, Lv H, Shi B and Hou P: Frequent amplification of AIB1, a critical oncogene modulating major signaling pathways, is associated with poor survival in gastric cancer. Oncotarget 6: 14344-14359, 2015.

28. Livak KJ and Schmittgen TD: Analysis of relative gene expression data using real-time quantitative PCR and the 2(-Delta Delta C(T)) method. Methods 25: 402-408, 2001.

29. Shi J, Qu Y, Li X, Sui F, Yao D, Yang Q, Shi B, Ji M and Hou P: Increased expression of EHF via gene amplification contributes to the activation of HER family signaling and associates with poor survival in gastric cancer. Cell Death Dis 7: e2442, 2016.

30. Guan H, Wei G, Wu J, Fang D, Liao Z, Xiao H, Li M and Li Y: Down-regulation of miR-218-2 and its host gene SLIT3 cooperate to promote invasion and progression of thyroid cancer. J Clin Endocrinol Metab 98: E1334-E1344, 2013.

31. Jang JH and Chung CP: Tenascin-C promotes cell survival by activation of Akt in human chondrosarcoma cell. Cancer Lett 229: 101-105, 2005.

32. Ding H, Jin M, Liu D, Wang S, Zhang J, Song X and Huang R: TenascinC promotes the migration of bone marrow stem cells via toll-like receptor 4-mediated signaling pathways: MAPK, AKT and Wnt. Mol Med Rep 17: 7603-7610, 2018.

33. Paron I, Berchtold S, Voros J, Shamarla M, Erkan M, Höfler H and Esposito I: Tenascin-C enhances pancreatic cancer cell growth and motility and affects cell adhesion through activation of the integrin pathway. PLoS One 6: e21684, 2011.

34. Xu Z, Liu D, Fan C, Luan L, Zhang X and Wang E: DIXDC1 increases the invasion and migration ability of non-small-cell lung cancer cells via the PI3K-AKT/AP-1 pathway. Mo Carcinog 53: 917-925, 2014.

35. Wu D, Peng F, Zhang B, Ingram AJ, Kelly DJ, Gilbert RE, Gao B and Krepinsky JC: PKC-betal mediates glucose-induced Akt activation and TGF-beta1 upregulation in mesangial cells. J Am Soc Nephrol 20: 554-566, 2009.
36. Peterziel H, Muller J, Danner A, Barbus S, Liu HK, Radlwimmer B, Pietsch T, Lichter P, Schutz G, Hess J and Angel P: Expression of podoplanin in human astrocytic brain tumors is controlled by the PI3K-AKT-AP-1 signaling pathway and promoter methylation. Neuro Oncol 14: 426-439, 2012.

37. Ho E and Ames BN: Low intracellular zinc induces oxidative DNA damage, disrupts p53, NFkappa B, and AP1 DNA binding, and affects DNA repair in a rat glioma cell line. Proc Natl Acad Sci USA 99: 16770-16775, 2002.

38. Han R, Li L, Ugalde AP, Tal A, Manber Z, Barbera EP, Chiara VD, Elkon R and Agami R: Functional CRISPR screen identifies AP1- associated enhancer regulating FOXF1 to modulate oncogene-induced senescence. Genome Biol 19: 118, 2018.

39. Yao CD, Haensel D, Gaddam S, Patel T, Atwood SX, Sarin KY, Whitson RJ, McKellar S, Shankar G, Aasi S, et al: AP-1 and TGFß cooperativity drives non-canonical Hedgehog signaling in resistant basal cell carcinoma. Nat Commun 11: 5079, 2020.

40. Karin M, Liu Z and Zandi E: AP-1 function and regulation. Curr Opin Cell Biol 9: 240-246, 1997

41. Kim SJ, Angel P, Lafyatis R, Hattori K, Kim KY, Sporn MB Karin M and Roberts AB: Autoinduction of transforming growth factor beta 1 is mediated by the AP-1 complex. Mol Cell Biol 10: $1492-1497,1990$

42. Kim SJ, Jeang KT, Glick AB, Sporn MB and Roberts AB Promoter sequences of the human transforming growth factor-beta 1 gene responsive to transforming growth factor-beta 1 autoinduction. J Biol Chem 264: 7041-7045, 1989.

43. Yue $J$ and Mulder KM: Requirement of Ras/MAPK pathway activation by transforming growth factor beta for transforming growth factor beta 1 production in a Smad-dependent pathway. J Biol Chem 275: 30765-30773, 2000.

44. Jinnin M, Ihn H, Asano Y, Yamane K, Trojanowska M, Tamaki K: Tenascin-C upregulation by transforming growth factor-beta in human dermal fibroblasts involves Smad3, Sp1, and Ets1. Oncogene 23: 1656-1667, 2004

45. Tie J, Pan Y, Zhao L, Wu K, Liu J, Sun S, Guo X, Wang B, Gang Y,Zhang Y, et al: MiR-218 inhibits invasion and metastasis of gastric cancer by targeting the Robol receptor. PLoS Genet 6: e1000879, 2010

46. Alajez NM, Lenarduzzi M, Ito E, Hui AB, Shi W, Bruce J, Yue S, Huang SH, Xu W, Waldron J, et al: MiR-218 suppresses nasopharyngeal cancer progression through downregulation of survivin and the SLIT2-ROBO1 pathway. Cancer Res 71: 2381-2391, 2011.

47. Shi ZM, Wang L, Shen H, Jiang CF, Ge X, Li DM, Wen YY, Sun HR, Pan MH, Li W, et al: Downregulation of miR-218 contributes to epithelial-mesenchymal transition and tumor metastasis in lung cancer by targeting Slug/ZEB2 signaling. Oncogene 36: 2577-2588, 2017.

48. Martinez I, Gardiner AS, Board KF, Monzon FA, Edwards RP and Khan SA: Human papillomavirus type 16 reduces the expression of microRNA-218 in cervical carcinoma cells. Oncogene 27: 2575-2582, 2008.

49. Uesugi A, Kozaki K, Tsuruta T, Furuta M, Morita K, Imoto I, Omura $\mathrm{K}$ and Inazawa $\mathrm{J}$ : The tumor suppressive microRNA miR-218 targets the mTOR component Rictor and inhibits AKT phosphorylation in oral cancer. Cancer Res 71: 5765-5778, 2011.

50. Tu Y, Gao X, Li G, Fu H, Cui D, Liu H, Jin W and Zhang Y: MicroRNA-218 inhibits glioma invasion, migration, proliferation, and cancer stem-like cell self-renewal by targeting the polycomb group gene Bmil.Cancer Res 73: 6046-6055, 2013

51. Jones FS and Jones PL: The tenascin family of ECM glycoproteins: Structure, function, and regulation during embryonic development and tissue remodeling. Dev Dyn 218: 235-259, 2000

52. Kii I, Nishiyama T, Li M, Matsumoto K, Saito M, Amizuka N and Kudo A: Incorporation of tenascin-C into the extracellular matrix by periostin underlies an extracellular meshwork architecture. J Biol Chem 285: 2028-2039, 2010.

53. Orend $\mathrm{G}$ and Chiquet-Ehrismann R: Tenascin-C induced signaling in cancer. Cancer Lett 244: 143-163, 2006.

54. Barrera LN,Evans A,Lane B,Brumskill S, OldfieldFE, Campbell F, Andrews T, Lu Z, Perez-Mancera PA, Liloglou T, et al: Fibroblasts from distinct pancreatic pathologies exhibit disease-specific properties. Cancer Res 80: 2861-2873, 2020.

This work is licensed under a Creative Commons Attribution-NonCommercial 4.0 International (CC BY-NC 4.0) License. 